\title{
Inventory model with inventory-dependent demand for deteriorating items in a single warehouse system
}

\author{
R.P. Tripathi ${ }^{\mathrm{a}^{*}}$ and S.M. Mishra ${ }^{\mathrm{b}}$
}

${ }^{a}$ Department of Mathematics, Graphic Era University, Dehradun (UK), India

${ }^{b}$ Research Scholar, UTU, Dehradun (UK) India

\section{H R O N I C L E}

Article history:

Received December 10, 2013

Received in revised format

25 June 2014

Accepted July 292014

Available online

August 12014

Keywords:

Inventory

Stock dependent demand rate

Shortage

Deteriorating items

\section{A B S T R A C T}

\begin{abstract}
This paper derives a deterministic inventory model for deteriorating items with inventory dependent demand rate. This study develops an order level inventory model with single warehouse where shortages are allowed and it is completely backlogged. The planning horizon is finite. This paper shows that there exists a unique optimal cycle time to minimize the total inventory cost per cycle. Truncated Taylor's series expansion is used for finding closed form optimal cycle time, optimal time to finish positive inventory and optimal total inventory cost per cycle. The numerical example is given to validate the proposed model. The sensitivity analysis of the solution with the changes of the values of parameters associated with the model has also been discussed.
\end{abstract}

\section{Introduction}

In classical EOQ model the demand rate is assumed to be constant, but in real life demand rate for physical goods may be time- dependent, price dependent and stock- dependent. It is observed that in supermarkets the demand rate is usually influenced by the demand in the stock. In business the presence of larger quantity of goods may attract more customers than that with a smaller quantity of goods. This phenomenon may valid for demand that have stock- level. Thus, building up a good inventory usually has a positive impact on the sales, and profit. Levin et al. (1972) observed that large group of consumer goods displayed in a supermarket will lead the buyer to purchase more. Baker and Urban (1988) presented an economic order quantity (EOQ) model for a power form inventory level dependent demand pattern. Mandal and Phaujdar (1989) established a production inventory model for deteriorating items with uniform production rate and stock- dependent demand. Silver and Peterson (1982) discussed that a sale at the retail level is proportional to the amount of inventory. Dutta and Pal (1990) developed inventory model for deteriorating items with the assumption that the demand rate is a linear function of the on - hand inventory by allowing shortages, which are completely

* Corresponding author

E-mail address: tripathi_rp0213@rediffmail.com (R.P. Tripathi)

(C) 2014 Growing Science Ltd. All rights reserved. doi: $10.5267 /$ j.uscm.2014.8.001 
backlogged for finite and infinite horizons. Soni and Shah (2008) formulated optimal ordering policies for retailer when demand is partially constant and partially dependent on the stock, and the supplier offers progressive credit periods to settle the account. You and Hsieh (2007) presented a continuous inventory model for finding the strategy for a firm that sells a seasonal item over a finite planning time.

There are varieties of inventory models with stock- dependent demand examined, extensively. The main two types of stock- dependent demand are usually considered (i) the linear form of $\alpha+\beta \mathrm{I}(\mathrm{t})$ and (ii) the power form of $\alpha\{\mathrm{I}(\mathrm{t})\}^{\beta}$, where $\alpha$ and $\beta$ are constants and $\mathrm{I}(\mathrm{t})$ is the inventory level at time ' $t$ '. In this direction, Zhou and Yang (2005) presented two warehouse inventory models for items with stock- level dependent demand rate. Mandal and Maiti (1999) developed an inventory model of damageable item with variable replenishment rate, stock-dependent demand rate and some units in hand. Giri and Chaudhuri (1998) presented an inventory model with power form stock-dependent demand and nonlinear holding cost. Chung (2003) discussed an algorithm for an inventory system with a power form stock-dependent demand. Balkhi and Benkherouf (2004) presented an inventory model for deteriorating items with a power form stock and time dependent demand rate for a finite time planning horizon. Urban (2005) provided an overview on inventory models with inventory level dependent demand and differentiated between the initial inventory dependent model and instantaneous inventory level dependent models. Gupta and Vrat (1986) developed an inventory model in which demand rate was a function of initial stock level. For seasonal products, the inventory problem with price and stock dependent demand cannot be ignored. Urban and Baker (1997) established a deterministic inventory model for demand having multivariate function of price, time value and inventory level. Some of the related works in this area have been accomplished by Wee (1995), Goh (1994), Dye (2002), Chung and Tsai (2001), Sarker et al. (1997), Chung (1989), Goyal and Chang (2009), Yang et al.(2010), Teng et al. (2011), etc.

Many products such as blood bank, food, medicine, voletile liquids, green vegetable and many others, deteriorate during their normal storage time. Thus, while determining the economic order quantity (EOQ) policy, the loss due to deterioration cannot be ignored. Ghare and Schrader (1963) who discussed the classical, no shortage inventory model with constant deterioration rate, initiated the analysis of deteriorating inventory. Covert and Philip (1973) extended Levin (1972) model and presented an EOQ model for a variable deterioration rate by assuming a two parameter Weibull distribution. Chang et al. (2003) established an EOQ model for deteriorating item in which the supplier provides a permissible delay to a purchaser if the order quantity is greater than or equal to a predetermined quantity. Tripathi and Pandey (2013) presented an inventory model for deteriorating items with Weibull distribution time dependent demand rate under trade credits.

In many cases, customers are used to a shipping delay and may be willing to a short time to receive their first choice. For popular items, the length of the waiting time for the next cycle time determines whether a backlog is accepted or rejected. Therefore the backlog rate should be variable and time dependent (waiting time). When shortages occur, it is assumed that there is either a complete backlog or the item lost. Tripathi (2012) developed an inventory model for items with an exponential demand rate under shortages and trade credits. Eduardo and Barron (2009) considered an EPQ inventory model for products manufactured in the environment of an imperfect production system that produces imperfect quality products. Dye et al. (2007) developed inventory model for deteriorating items with price dependent demand under shortages. Pentico et al. (2009) developed the deterministic EPQ with partial backordering. Chiu (2008) presented a simple algebraic method to replace the use of calculus for determining the optimal lot size. There are many other studies on production inventory model with shortages and partially backlogs such as Wee (1995), Hollier and Mark (1983) Goyal and Giri (2003), Park (1982) and others. 
The rest of the paper is organized as follows. The next section presents notations and assumptions followed by mathematical formulation in section 3. In section 4, optimal solutions are given followed by numerical example in section 5. Section 6 indicates the sensitivity analysis. Finally, conclusion and future research is given the last section 7.

\section{Notations and Assumptions}

The following notations are used throughout the paper:

$\begin{array}{ll}\mathrm{D} \equiv \mathrm{D}(\mathrm{t})=\alpha+\beta \mathrm{I}(\mathrm{t}) & \text { Demand rate } \alpha>0,0<\beta<1 \\ \alpha & \text { Consumption rate } \\ \beta & \text { Stock dependent consumption rate } \\ \mathrm{I}(\mathrm{t}) & \text { The inventory level at any time } \mathrm{t} . \\ \theta & \text { Rate of deterioration } 0<\theta<1 \\ \mathrm{~T} & \text { Total cycle time } \\ \mathrm{q}_{1} & \text { Initial stock-level at the beginning of every inventory } \\ \mathrm{SC} & \text { Shortage cost } \\ \mathrm{s} & \text { Shortage cost per unit } \\ \mathrm{HC} & \text { Holding cost } \\ \mathrm{h} & \text { Holding cost per unit } \\ \mathrm{D}_{\mathrm{T}} & \text { Total deteriorating item } \\ \mathrm{c} & \text { Deteriorating cost per unit } \\ \mathrm{q}_{2} & \text { Maximum shortage level } \\ \mathrm{TIC} & \text { Total inventory cost per cycle } \\ \mathrm{DC} & \text { Deteriorating cost } \\ \mathrm{k} & \text { Ordering cost per order (OC) } \\ \mathrm{TIC} & \text { Optimal Total inventory cost per cycle } \\ \end{array}$

In addition, the following assumptions exist in this manuscript:

1. The demand rate $\mathrm{D}$ is known and stock-level dependent i.e. $\mathrm{D} \equiv \mathrm{D}(\mathrm{t})=\alpha+\beta \mathrm{I}(\mathrm{t}), \alpha>0,0<\beta<1$.

2. Shortages are allowed and fully backlogged.

3. Deterioration rate $\theta$ is constant and is age specific failure rate.

4. The scheduling period is constant.

5. Lead time is zero.

6. Initial stock-level is raised to order level at the beginning of every period.

7. Deterioration of the units is considered only after they have being received into the inventory.

\section{Mathematical Formulation}

The inventory level decreases to meet demand and partially due to deterioration. By this process the stock reaches zero level at $\mathrm{t}=\mathrm{T}_{1}$. Again shortages occur and accumulate to the level $\mathrm{q}_{2}$ at $\mathrm{t}=\mathrm{T}$. The differential equations in $(0, \mathrm{~T})$ are given by 
$\frac{d I(t)}{d t}+\theta I(t)=-\{\alpha+\beta I(t)\}, 0 \leq \mathrm{t} \leq \mathrm{T}_{1}$

$\frac{d I(t)}{d t}=-\alpha, \quad \mathrm{T}_{1} \leq \mathrm{t} \leq \mathrm{T}$

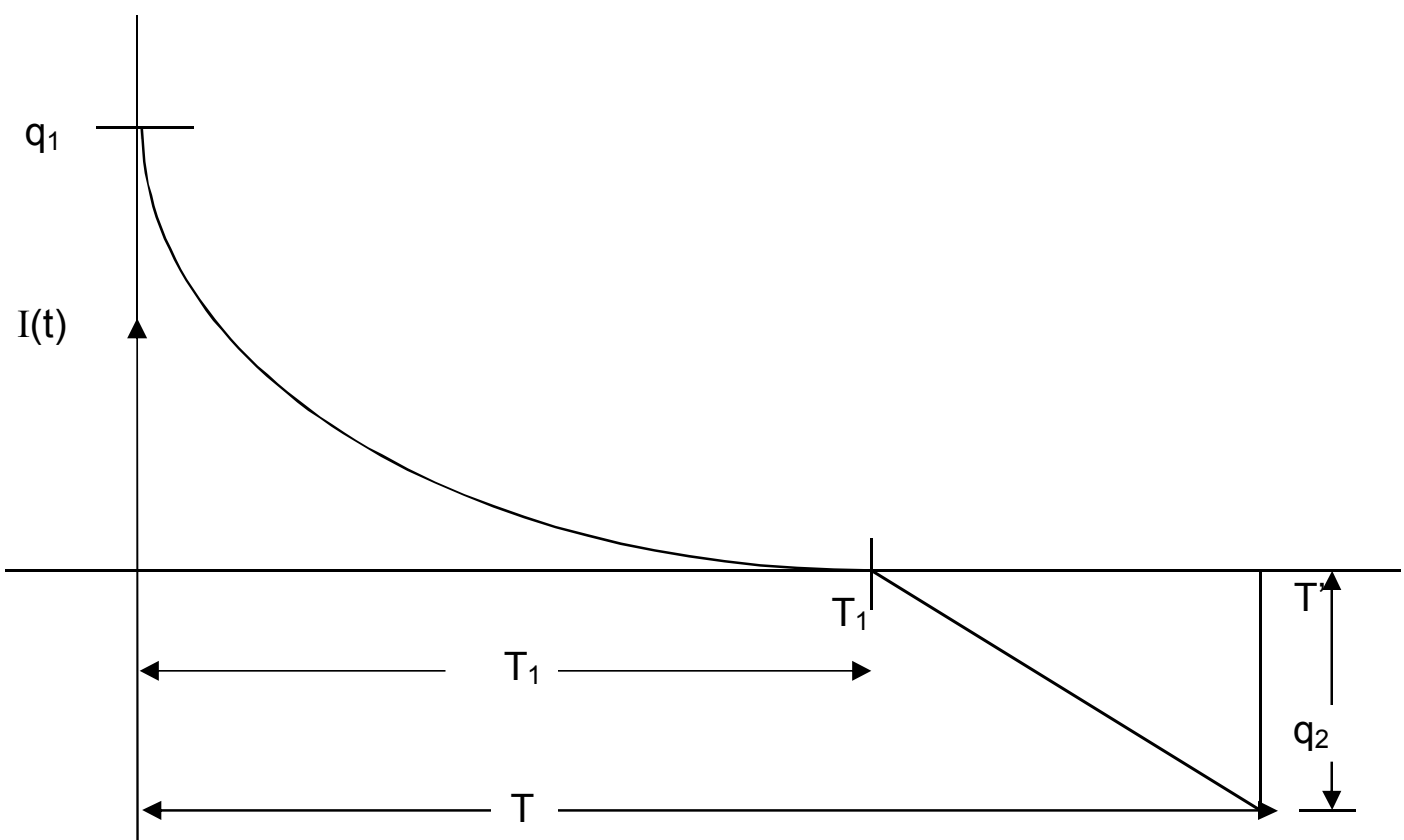

Fig. 1. Inventory level vs time

Solution of Eq. (1) with boundary conditions $\mathrm{I}(0)=-\mathrm{q}_{1}$ and $\mathrm{I}\left(\mathrm{T}_{1}\right)=0$ yields

$$
\begin{aligned}
& I(t)=\frac{\alpha}{\theta+\beta}\left\{e^{(\theta+\beta)\left(T_{1}-t\right)}-1\right\}, 0 \leq \mathrm{t} \leq \mathrm{T}_{1} \\
& I(0)=q_{1}=\frac{\alpha}{\theta+\beta}\left\{e^{(\theta+\beta) T_{1}}-1\right\}
\end{aligned}
$$

from Eq. (4), we get

$$
T_{1}=\frac{1}{\theta+\beta} \log \left\{1+\frac{(\theta+\beta) q_{1}}{\alpha}\right\}
$$

The solution of Eq. (2) with the conditions $\mathrm{I}\left(\mathrm{T}_{1}\right)=0$ and $\mathrm{I}(\mathrm{T})=-\mathrm{q}_{2}$, is given by

$$
I(t)=\alpha\left(T_{1}-t\right), \mathrm{T}_{1} \leq \mathrm{t} \leq \mathrm{T}
$$

Using the condition $I(T)=-q_{2}$ in Eq. (6), we obtain

$$
q_{2}=\alpha\left[T-\frac{1}{\theta+\beta} \log \left\{1+\frac{(\theta+\beta) q_{1}}{\alpha}\right\}\right] \text {. }
$$

Total deteriorating units during the time $\left(0, \mathrm{~T}_{1}\right)$ is given by 
$D_{T}=\int_{0}^{T_{1}} \theta I(t) d t=\frac{\alpha \theta}{\theta+\beta}\left\{\frac{e^{(\theta+\beta) T_{1}}-1}{\theta+\beta}-T_{1}\right\}, 0 \leq \mathrm{t} \leq \mathrm{T}_{1}$,

where $T_{1}$ is defined in Eq. (5). The deteriorating cost is given by

$$
D C=c D_{T}=\frac{c \alpha \theta}{\theta+\beta}\left\{\frac{e^{(\theta+\beta) T_{1}}-1}{\theta+\beta}-T_{1}\right\}, 0 \leq \mathrm{t} \leq \mathrm{T}_{1}
$$

Holding cost over the period $\left(0, \mathrm{~T}_{1}\right)$ is given by

$$
H C=h \int_{0}^{T_{1}} I(t) d t=\frac{h \alpha}{\theta+\beta}\left\{\frac{e^{(\theta+\beta) T_{1}}-1}{\theta+\beta}-T_{1}\right\}, 0 \leq \mathrm{t} \leq \mathrm{T}_{1}
$$

Shortage cost is given by

$$
S C=s \int_{0}^{T_{1}}-I(t) d t=\frac{s \alpha}{2}\left(\mathrm{~T}-\mathrm{T}_{1}\right)^{2} .
$$

Hence total inventory cost per cycle is given by

$$
\begin{aligned}
& T I C=\frac{1}{T}[O C+S C+H C+C D], \\
& T I C=\frac{1}{T}\left[k+\frac{s \alpha}{2}\left(T-T_{1}\right)^{2}+\frac{\alpha(h+c \theta)}{\theta+\beta}\left\{\frac{e^{(\theta+\beta) T_{1}}-1}{\theta+\beta}-T_{1}\right\}\right] .
\end{aligned}
$$

\section{Determination of Optimal Solution}

For finding optimal solution differentiating Eq. (12) partially with respect to $\mathrm{T}$ and $\mathrm{T}_{1}$ two times we get

$$
\begin{aligned}
& \frac{\partial(T I C)}{\partial T}=-\frac{1}{T^{2}}\left[k+\frac{s \alpha\left(T-T_{1}\right)^{2}}{2}+\frac{\alpha(h+c \theta)}{\theta+\beta}\left\{\frac{e^{(\theta+\beta) T_{1}}-1}{\theta+\beta}-T_{1}\right\}\right]+\frac{s \alpha\left(T-T_{1}\right)}{T} \\
& \frac{\partial^{2}(T I C)}{\partial T^{2}}=\frac{2}{T^{3}}\left[k+\frac{s \alpha\left(T-T_{1}\right)^{2}}{2}+\frac{\alpha(h+c \theta)}{\theta+\beta}\left\{\frac{e^{(\theta+\beta) T_{1}}-1}{\theta+\beta}-T_{1}\right\}\right]+\frac{s \alpha}{T^{2}}\left(2 T_{1}-T\right)>0 \\
& \frac{\partial(T I C)}{\partial T_{1}}=\frac{\alpha}{T}\left\{-s\left(T-T_{1}\right)+\frac{(h+c \theta)}{\theta+\beta}\left(e^{(\theta+\beta) T_{1}}-1\right)\right\} \\
& \frac{\partial^{2}(T I C)}{\partial T_{1}^{2}}=\frac{\alpha}{T}\left[s+(h+c \theta) e^{(\theta+\beta) T_{1}}\right]>0 \\
& \frac{\partial^{2}(T I C)}{\partial T \partial T_{1}}=-\frac{\alpha}{T^{2}}\left\{s T_{1}+\frac{(h+c \theta)}{\theta+\beta}\left(e^{(\theta+\beta)}-1\right)\right\}<0
\end{aligned}
$$

Since $\left(\frac{\partial^{2}(T I C)}{\partial T^{2}}\right)\left(\frac{\partial^{2}(T I C)}{\partial T_{1}^{2}}\right)-\left(\frac{\partial^{2}(T I C)}{\partial T \partial T_{1}}\right)^{2}>0$ and $\frac{\partial^{2}(T I C)}{\partial T^{2}}>0, \quad \frac{\partial^{2}(T I C)}{\partial T_{1}^{2}}>0$, the optimal values $\mathrm{TIC}=\mathrm{TIC}^{*}$ is minimum. Optimal (minimum) values of $T=T^{*}$ and $T=T_{1}^{*}$ is obtained by solving 
$\frac{\partial(T I C)}{\partial T}=0$, and $\frac{\partial(T I C)}{\partial T_{1}}=0$ simultaneously is minimum. Putting $\frac{\partial(T I C)}{\partial T}=0$, and $\frac{\partial(T I C)}{\partial T_{1}}=0$.We obtain

$$
\begin{aligned}
& 2 k-s \alpha\left(T^{2}-T_{1}^{2}\right)+\frac{2 \alpha(h+c \theta)}{\theta+\beta}\left(\frac{e^{(\theta+\beta) T_{1}}-1}{\theta+\beta}-T_{1}\right)=0, \\
& s\left(T-T_{1}\right)-\frac{(h+c \theta)}{\theta+\beta}\left(e^{(\theta+\beta) T_{1}}-1\right)=0 .
\end{aligned}
$$

Truncated Taylor's series is used in exponential terms for finding closed form solution i.e.

$$
\begin{aligned}
& e^{(\theta+\beta) T_{1}} \approx 1+(\theta+\beta) T_{1}+\frac{(\theta+\beta)^{2} T_{1}^{2}}{2}, \text { Eq. (18) and Eq. (19) become } \\
& \alpha(h+s+c \theta) T_{1}^{2}-s \alpha T^{2}+2 k=0 \\
& (h+c \theta)(\theta+\beta) T_{1}^{2}+2(h+s+c \theta) T_{1}-2 s T=0
\end{aligned}
$$

Solving Eq. (20) and Eq. (21) simultaneously, we obtain optimal $\mathrm{T}=\mathrm{T}^{*}$ and $\mathrm{T}_{1}=\mathrm{T}_{1}{ }^{*}$

\section{Numerical Example}

Given the following parameters in appropriate units, $\theta=0.2, \alpha=500, \mathrm{~h}=10, \mathrm{~s}=1000, \mathrm{k}=20, \mathrm{c}=4$, we get $\mathrm{T}=\mathrm{T}^{*}=0.084247439$ year $\mathrm{T}_{1}=\mathrm{T}_{1}{ }^{*}=0.08331021$ year, and $\mathrm{TIC}=\mathrm{TIC}^{*}=\$ 468.6135991$.

\section{Sensitivity Analysis}

By using the same data as in above numerical example, we study the effect of the changes in a single parameter on the optimal solutions of $\mathrm{T}_{1}=\mathrm{T}_{1}{ }^{*}, \mathrm{~T}=\mathrm{T}^{*}$ and $\mathrm{Z}\left(\mathrm{T}_{1}, \mathrm{~T}\right)=\mathrm{Z}^{*}\left(\mathrm{~T}_{1}, \mathrm{~T}\right)$.

Case I: Variation of consumption rate $\alpha$

Table 1a

Variation of consumption rate $\alpha$

\begin{tabular}{cccc}
\hline$\alpha$ & $\mathrm{T}=\mathrm{T}^{*}$ & $\mathrm{~T}_{1}=\mathrm{T}_{1}{ }^{*}$ & $\mathrm{TIC}=\mathrm{TIC}^{*}$ \\
\hline 500 & 0.084247439 & 0.08331021 & 468.6135991 \\
550 & 0.080421804 & 0.07952874 & 491.1854657 \\
600 & 0.077077804 & 0.07622322 & 512.7508545 \\
650 & 0.074121928 & 0.07330126 & 533.4344034 \\
700 & 0.071484280 & 0.07069380 & 553.3361639 \\
750 & 0.069111434 & 0.06834805 & 572.5385937 \\
800 & 0.066961739 & 0.06622285 & 591.1106321 \\
850 & 0.065002190 & 0.06428559 & 609.1105782 \\
900 & 0.063206259 & 0.06251005 & 626.5882238 \\
\hline
\end{tabular}


Case II: Variation of deterioration rate $\theta$

Table 1b

Variation of deterioration rate $\theta$

\begin{tabular}{cccc}
\hline$\theta$ & $\mathrm{T}=\mathrm{T}^{*}$ & $\mathrm{~T}_{1}=\mathrm{T}_{1}{ }^{*}$ & $\mathrm{TIC}=\mathrm{TIC}^{*}$ \\
\hline 0.25 & 0.08327689 & 0.08235088 & 473.445575 \\
0.30 & 0.082336034 & 0.08142089 & 478.2367439 \\
0.35 & 0.081423382 & 0.08051877 & 482.9891115 \\
0.40 & 0.080537588 & 0.79643194 & 487.7034512 \\
0.45 & 0.079677357 & 0.78792877 & 492.3812089 \\
0.50 & 0.078841505 & 0.07796664 & 497.0230666 \\
0.55 & 0.078028907 & 0.077163395 & 499.4695849 \\
0.60 & 0.077238521 & 0.076382091 & 506.2024369 \\
0.65 & 0.076469355 & 0.07562176 & 510.7418448 \\
\hline
\end{tabular}

Case III: Variation of ordering cost per order $\mathrm{k}$

Table 1(c)

Variation of ordering cost per order $\mathrm{k}$

\begin{tabular}{cccc}
\hline $\mathrm{k}$ & $\mathrm{T}=\mathrm{T}^{*}$ & $\mathrm{~T}_{1}=\mathrm{T}_{1}{ }^{*}$ & $\mathrm{TIC}=\mathrm{TIC}^{*}$ \\
\hline 40 & 0.117924913 & 0.11659231 & 666.3016397 \\
60 & 0.143332216 & 0.14169351 & 819.3530278 \\
80 & 0.164475155 & 0.16257660 & 949.2777956 \\
100 & 0.182902371 & 0.18077355 & 1064.410681 \\
120 & 0.199406675 & 0.19706862 & 1169.02789 \\
140 & 0.214458271 & 0.21192693 & 1265.670640 \\
160 & 0.228363030 & 0.225615104 & 1355.995273 \\
180 & 0.241333055 & 0.23845075 & 1441.152706 \\
200 & 0.253522562 & 0.25047860 & 1521.981199 \\
\hline
\end{tabular}

Case IV: Variation of shortage costs

Table 1(d)

Variation of shortage cost $\mathrm{s}$

\begin{tabular}{cccc}
\hline $\mathrm{s}$ & $\mathrm{T}=\mathrm{T}^{*}$ & $\mathrm{~T}_{1}=\mathrm{T}_{1}{ }^{*}$ & $\mathrm{TIC}=\mathrm{TIC}$ \\
\hline 1100 & 0.088161077 & 0.08726689 & 469.3667993 \\
1300 & 0.095471557 & 0.09464804 & 473.1333754 \\
1500 & 0.102218388 & 0.10145089 & 479.8747421 \\
1700 & 0.108510088 & 0.10778841 & 485.8346361 \\
1900 & 0.114424356 & 0.11374106 & 493.5669116 \\
2100 & 0.120019045 & 0.11936851 & 501.7939039 \\
2300 & 0.125338633 & 0.12471649 & 510.3357624 \\
2500 & 0.130418180 & 0.12982095 & 519.0722780 \\
2700 & 0.135285907 & 0.13471077 & 527.9211419 \\
\hline
\end{tabular}

From the results of Table 1a to Table 1d, the following observations can be stated,

(i) From Table 1(a), we observe that any increase of consumption rate ' $\alpha$ ' results decrease in optimal cycle time $\mathrm{T}=\mathrm{T}^{*}$, optimal time to finish positive inventory $\mathrm{T}_{1}=\mathrm{T}_{1}{ }^{*}$ and increase of optimal total inventory cost $\mathrm{TIC}=\mathrm{TIC}^{*}$. 
(ii) From Table 1(b), it can be easily seen that any increase of deterioration rate ' $\theta$ ' results a decrease in $\mathrm{T}=\mathrm{T}^{*}$, optimal time to finish positive inventory $\mathrm{T}_{1}=\mathrm{T}_{1}{ }^{*}$ and optimal increase total inventory cost $\mathrm{TIC}=\mathrm{TIC}^{*}$.

(iii) From Table 1(c) any increase of ordering cost per order ' $\mathrm{k}$ ' results to any increase in optimal cycle time $\mathrm{T}=\mathrm{T}^{*}$, optimal time to finish positive inventory $\mathrm{T}_{1}=\mathrm{T}_{1}{ }^{*}$ and optimal total inventory cost $\mathrm{TIC}=\mathrm{TIC}^{*}$.

(iv) From Table 1(d) it can be observed that any increase of shortage cost ' $\mathrm{s}$ ' results to any increase in optimal cycle time $\mathrm{T}=\mathrm{T}^{*}$, optimal time to finish positive inventory $\mathrm{T}_{1}=\mathrm{T}_{1}{ }^{*}$ and optimal total inventory cost $\mathrm{TIC}=\mathrm{TIC}^{*}$.

\section{Conclusion and Future Research}

In this study, EOQ model for deteriorating items with stock - dependent demand in a single warehouse has been developed. Since stock dependent consumption rate ' $\beta$ ' is small, we simplified the model by assuming $\beta \mathrm{t}$ as a small value. While dealing with time - varying demand pattern, the researchers usually take demand rate to be linearly time dependent. It is rarely seen to occur for any manufacturing commodity. Some researcher take exponential rate, but it is doubtful whether the real market demand of any commodity can really rise or fall, exponentially. The traditional parameters of holding cost are assumed to be (i) constant, (ii) exponential time dependent and (iii) stock dependent. Most of the researchers considered the holding cost to be constant. However, holding cost cannot constant over time due to changes in the time value of money and in the price index.

This paper investigated the effect of a single warehouse system within the EOQ framework. In this study, shortages were allowed and completely backlogged. Taylor's series approximation has been used for finding closed form solution. The deterioration factor has been taken into consideration in the model as almost all items undergo either direct spoilage or physical decay in the course of time; deterioration is a natural feature in inventory system. Numerical example is given to prove the propose model. Form the sensitivity analysis we see that if shortage cost and consumption rate increase, total cost will also increase.

The proposed model can be extended in several ways. For instance, we may extend the model for exponential demand rate, quantity discount, inflation rate, time value of money. We could consider the demand as a function of price, stock- dependent, time product quantity, etc. Finally, we could generalize the model for quantity discount and others.

\section{References}

Baker, R.C., \& Urban, T.L. (1988). A deterministic inventory system with an inventory-leveldependent demand rate. Journal of Operations Research Society, 39, 823-831

Balkhi, Z.T., \& benkherouf, L. (2004). On an inventory model for deteriorating items with stockdependent and time varying demand rates. Computers and Operations Research, 31, 223-240.

Covert, R.B., \& Philip, G.S. (1973). An EOQ model with weibull distribution deterioration. AIIIE Transactions 5, 323-326.

Chang, C.T. Ouyang, L.Y., \& Teng, J.T. (2003). An EOQ model for deteriorating items under supplier credit linked to order quantity. Applied Mathematical Modeling, 27, 983-996.

Chiu, S.W. (2008). Production lot size problem with failure in repair and backlogging derived without derivatives. European Journal of Operational Research,188, 610-615. 
Chung, K.J. (2003). An algorithm for an inventory model with inventory level-demand rate.

Computers and Operations Research, 30, 1311-1317.

Chung, K.J., \& Tsai, S.F. (2001). Inventory systems for deteriorating items with shortages and a linear trend in demand taking account of time value. Computers and Operations Research, 28(9), 915-934.

Chung, K.H. (1989). Inventory control and trade credit revisted. Journal of the operational research society, 40, 495-498.

Datta, T.K., \& Pal, A.K. (1990). A note on an inventory model with inventory- level dependent demand rate. Journal of Operational Research Society, 41, 971-975.

Dye, C.Y. (2002). A deterministic inventory model with stock- dependent demand and partial backlogging under condition of permissible delay in payments, Opsearch, 39(3), 189-201.

Dye, C.Y. Hsieh, T.P., \& Ouyang, L.Y. (2007). Determining optimal selling price and lot size with a varying rate of deterioration and exponential partial backlogging. European Journal of Operational Research, 181,668-678.

Eduardo, L., \& Barron, C. (2009). Economic production quantity with rework process at a single stage manufacturing system with planned backorders. Computers and Industrial Engineering, 57 , $1105-1113$

Ghare, P.M., \& Schrader, G.P. (1963). A model for an exponentially decaying inventory. Journal of Industrial Engineering, 14(5), 238-243.

Giri, B.C., \& Chaudhuri, K.S. (1998). Deterministic models of perishable inventory with stockdependent demand rate and nonlinear holding cost. European Journal of Operational Research, $105,467-474$.

Goh, M. (1994). EOQ models with general demand and holding cost function.

European Journal of Operational Research, 73, 50-54.

Goyal, S.K., \& Chang, C.T. (2009). Optimal ordering and transfer policy for an inventory with stockdependent demand. European Journal of Operational Research, 196, 177-185.

Goyal, S.K., \& Giri, B.C. (2003). The production inventory problem of a product with time varying demand, production and deterioration rates. European Journal of Operational Research, 147, 549557.

Gupta, R., \& Vrat, P. (1986). Inventory model for stock-dependent consumption rate. Opsearch, 23, 19-24.

Hollier, R.H., \& Mak, K.L. (1983). Inventory replenishment policies for deteriorating items in a declining market. International Journal of Production Research, 21(6), 813-826.

Levin, R.I., McLaughlin, C.P., Lamone, R.P., \& Kottas, J.F. (1972). Production Operation Management: Contemporary Policy for Managing Operating System. McGraw- Hill, New York, 373.

Mandal, B.N., \& Phaujdar, S. (1989). A note on an inventory model with stock-dependent consumption rate, Opsearch, 26, 43-46.

Mandal, B., \& Maiti, M. (1999). Inventory of damageable items with variable replenishment rate, stock dependent demand rate and some units in hand. Applied Mathematical Modelling, 23, 799807.

Park, K.S. (1982). Inventory model with partial backorders. International Journal of System Science, 13-12, 1313-1317. 
Pentico, D.W., Drake, M.J., \& Toews, C. (2009). The deterministic EPQ with partial backordering: A new approach. Omega, 37, 624-636.

Sarker, B.R., Mukherjee, S., \& Balan, C.V. (1997). An order level lot size inventory model with inventory level dependent demand and deterioration. . International Journal of Production Economics, 48, 227-236.

Soni, H., \& Shah, N.H. (2008). Optimal ordering policy for stock dependent demand rate under progressive payment scheme. European Journal of Operational Research, 184, 91-100.

Silver, E.A., \& Peterson, R. (1982). Decision System for inventory management and production planning, $2^{\text {nd }}$ ed., Wiley, New York.

Teng, J.T., Krommyda, I.P., Skouri, K., \& Lou, K.R. (2011). A comparative extension of optimal ordering policy for stock- dependent demand under progressive payment scheme. European Journal of Operational Research, 215, 97-104.

Tripathi, R.P., \& Pandey, H.S. (2013). An EOQ model for deteriorating items with Weibull time dependent demand rate under trade credits. International Journal of Information and management Sciences, 24, 329-347.

Tripathi, R.P. (2012). An inventory model with shortages and exponential demand rate. Under permissible delay in payments. International Journal of Management Science and Engineering Management, 7(2), 129-134.

Urban T.L., \& Baker, R.C. (1997). Optimal ordering and pricing policies in a single period environment with multi variate demand and markdowns. European Journal of Operational Research, 103, 573-583.

Urban, T.L. (2005). Inventory models with inventory- level dependent demand: A comparative review and unifying theory. European Journal of Operational Research, 162, 792-804.

Wee, H.M. (1995). Joint pricing and replenishment policy for deteriorating inventory with declining market. International Journal of Production Economics, 40, 163-171.

Wee, H.M. (1995). A deterministic lot size- size inventory model for deteriorating items with shortages and a declining market. Computers and Operations Research, 22(3), 345-356.

Yang, H.L., Teng, J.T., \& Chern, M.C. (2010). An inventory model under inflation for deteriorating items with stock- dependent consumption rate and partial backlogging shortages. International Journal of Production Economics, 123, 8-19.

You, P.S., \& Hsieh, Y.C. (2007). An EOQ model with stock and price sensitive demand. Mathematical and Computer Modelling, 45, 933-942.

Zhou, Y.W., \& Yang, S.L. (2005). A two warehouse inventory model for item with stock- level dependent demand rate. International Journal of Production Economics, 95, 215-228. 